\title{
First molecular description of Macracanthorhynchus hirudinaceus in wild boars from Italy with pathomorphological and epidemiological insights
}

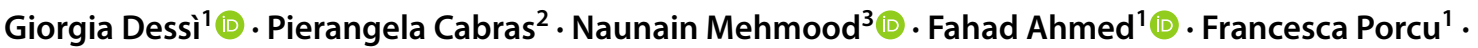

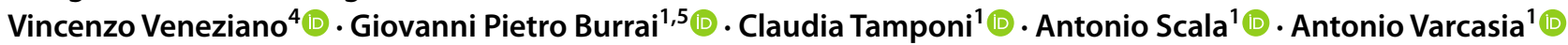

Received: 14 August 2021 / Accepted: 16 November 2021 / Published online: 25 November 2021

(c) The Author(s), under exclusive licence to Springer-Verlag GmbH Germany, part of Springer Nature 2021

\begin{abstract}
Macracanthorhynchus hirudinaceus is a zoonotic parasite affecting suids worldwide which are the definitive hosts for this helminth species. Macracanthorhynchus hirudinaceus is of significant economic and management concern due to its pathogenicity, causing intestinal obstruction and perforation in the definitive hosts. Current study is the preliminary investigation from Sardinia, Italy, reporting the pathomorphological findings and molecular characterization of M. hirudinaceus in the wild boars (Sus scrofa meridionalis). A total of 59 wild boars were examined showing acanthocephalan infection in $8(13.6 \%)$ animals. In total, 49 parasites were collected with a mean intensity of 6.1 . Comparatively higher infection levels were observed for males (16.7\%) and young boars (14.3\%); however, these epidemiological differences were statistically nonsignificant. Histopathological examination revealed the presence of a variable number of nodules $(\sim 5 \mathrm{~mm})$ in the intestine of M. hirudinaceus infested animals surrounded by a hyperemic-hemorrhagic halo. Several parasites were recovered from the intestinal lumen attached by the means of characteristic hooks showing necrosis in muscle layers. A moderate number of plump reactive fibroblasts and lesser numbers of fibrocytes were embedded with and at the borders of the inflammatory nodules in a moderate amount of homogeneous intensely eosinophilic fibrillary material rupturing the cell membrane. For molecular characterization, six isolated worms were amplified for the partial mitochondrial coxl gene showing distinct interindividual variations. This first pathological and molecular description from southern Europe provided new knowledge about the diffusion of $M$. hirudinaceus in wild boars, furthering the research into the origin and transmission status of $M$. hirudinaceus in endemic localities.
\end{abstract}

Keywords Acanthocephala $\cdot$ Macracanthorhynchus hirudinaceus $\cdot$ Italy $\cdot$ mtDNA $\cdot$ coxI

\section{Introduction}

Section Editor: Hiroshi Sato

Claudia Tamponi

cltamponi@uniss.it

1 Department of Veterinary Medicine, University of Sassari, Sassari, Italy

2 Istituto Zooprofilattico Sperimentale Della Sardegna, Tortolì, Italy

3 Department of Zoology, University of Sargodha, Sargodha, Pakistan

4 Department of Veterinary Medicine and Animal Productions, University of Naples Federico II, Naples, Italy

5 Mediterranean Center for Disease Control (MCDC), University of Sassari, Sassari, Italy
The wild boars (Sus scrofa) are distributed throughout the Europe, Asia and North Africa (Wilson 2005). In the last decade their population has increased remarkably in most areas of Europe, including Italy (Pittiglio et al. 2018). To date, the wild boar population in Europe counts nearly four million individuals with abundance of these ungulates approximately doubled from 500,000 in 2010 to 1 million in 2020 in Italy (Iacolina et al. 2018; ISPRA, 2020). The endemic subspecies, Sus scrofa meridionalis, is spread throughout the Sardinian Island, occupying various habitats including low Mediterranean maquis, woodlands, both uncultivated and cultivated lands and pastures (Iacolina et al. 2016; Lombardini et al. 2017). 
The wild boars are classified as one of the most invasive animal species in the world according to the International Union for the Conservation of Nature: Species Survival Commission (IUCN SSC), not only because of the environmental concern, but also due to significant damage to agricultural and natural habitats, and key infectious disease reservoirs transferring diseases to animals and humans (ISSG 2013, Fredriksson-Ahomaa 2018). Being omnivorous with high adaptation capacity, wild boars feed on small mammals, invertebrates, carrions and tubers and could therefore host a high diversity of gastro-intestinal helminths that have great public health importance (Solaymani-Mohammadi et al. 2003).

Among the helminths of wild boars is the zoonotic acanthocephalan Macracanthorhynchus hirudinaceus (Leng et al. 1983; Schmidt 1971; Radomyos et al. 1989). The life cycle is indirect, the adult stage infects the small intestine of wild boars, the definitive hosts and can be accidentally transmitted to humans by ingestion of the intermediate host, arthropods, usually coleoptera from Scarabaeidae family (Melolontha vulgaris, Cetonia aurata, Polyphilla fullo, Anomalia vitis). The most important intermediate hosts in the United States are the June beetles (Cotinis nitida), New World scarab beetles (genus Phyllophaga), and other beetle species that feed primarily on dung (Pavlović et al. 2010). Adult worms possess a retractable proboscis armed with hooks and granulomatous lesions are often found at the site of attachment. Since acanthocephalans lack digestive tract, nutrients uptake occurs directly through the tegument (Bowman et al. 2003). Female worms measure up to $40 \mathrm{~cm}$ in length, while males are smaller and measure up to $10 \mathrm{~cm}$ (Mowlavi et al. 2006). Mature eggs released through the female's uterine are passed in the feces of the host. Deep brown in color and spindle shaped, eggs measure $110 \mu \mathrm{m}$ by $65 \mu \mathrm{m}$ having three layered shell and well developed acanthors. The eggs are capable of surviving under extreme climatic conditions. After being ingested by dung beetles, the acanthor larva develops to an infective cystacanth stage in around 3 months. Wild boars become infected by ingesting beetle grubs with the cystacanths developing into adults (Urquhart et al. 1996, Bowman et al. 2003, Marchiondo 2019).

Despite the large population and wide distribution of wild boars in Sardinia, very few studies on parasites of these animals have been carried out on the island (Bandino et al. 2015; Bonelli et al. 2020; Setsuda et al. 2020). Regarding $M$. hirudinaceus, the only study in wild boars in Sardinia was published in conference proceedings and refers to a case report (Pilo et al. 2012). Therefore, no data on the epidemiology and molecular characterization of this parasite in Sardinian wild boars are currently available. To fill this knowledge gap, the current study aimed to assess the prevalence of M. hirudinaceus in wild boars in Sardinia, as well as to report the pathomorphological findings and the molecular genetic characteristics of this parasite for the first time from Southern Europe to have a better understanding of genetic diversity of its population in Sardinia, Italy.

\section{Material and methods}

\section{Sample collection}

From 2009 to 2020 , a total of 59 wild boars were examined at Istituto Zooprofilattico Sperimentale della Sardegna, Tortolì, Sardinia. Animals considered in this study were culled during the hunting seasons. At necropsy, data about age, sex, and hunting site were recorded. Based on tooth development, animals were classified as juveniles ( $<18$ months of age) and adults ( $\geq 18$ months of age) (Massei and Toso 1993; Papini et al. 2018). The gastrointestinal tract was opened and macroscopically examined for the presence of parasites and pathological lesions. All acanthocephalans were collected and stored in $70 \%$ alcohol until morphological identification and biomolecular analysis at Parasitology Laboratory of the Veterinary Teaching Hospital of the University of Sassari, Italy. Morphological identification of M. hirudinaceus was performed using the morphological keys available in literature (Petrochenko, 1958; Richardson 2005).

\section{Histological examination}

Selected tissue samples of the intestinal tracts showing acanthocephalan lesions were fixed in $10 \%$ buffered formalin, dehydrated with a series of increasing alcohol concentration and cleared in xylene and were subsequently embedded in paraffin. Multiple sections of $3 \mu \mathrm{m}$ thickness were stained with hematoxylin and eosin (H.E.) and evaluated at light microscopy. Tissues were imaged using Nikon Eclipse 80i and digital computer images were recorded with a Nikon Ds-fil camera.

\section{Biomolecular analysis}

DNA from six collected worms was extracted using G-spin ${ }^{\mathrm{TM}}$ Total DNA Extraction kit (iNtRON Biotechnology, Korea) according to the manufacturer's instructions. PCR amplification of the mitochondrial cytochrome $c$ oxidase subunit 1 gene ( $\operatorname{cox} 1$ ) was performed using one set of primers, Acanth_Cox1-F1 (5'-TTTGGAGGGGTTTGATGG GT-3') and Acanth_Cox1-R4 (5'-CCCCAGACATTCTTC TCTCCA-3'), and the same conditions previously described (Kamimura et al. 2018). PCR products were purified using Nucleospin Gel and PCR Clean Up (Macherey-Nagel GmbH \& Co. KG, Düren, Germany) and sent to an external sequencing service (Eurofins Genomics, Ebersberg, 
Germany). The sequences were obtained using primers Acanth_cox1-F4 (5'-TTGGGTATTTGGGCATGGTG-3') and Acanth_cox1-R2 (5'-CACCATGCCCAAATACCC AA-3') employed exclusively for sequencing (Kamimura et al. 2018) of the partial coxl gene and compared with the reference sequences for M. hirudinaceus (FR856886, Weber et al. 2013; LC350021, Kamimura et al. 2018) available on the NCBI database using BLAST algorithm (https://blast. ncbi.nlm.nih.gov/Blast.cgi).

Multiple alignment of the obtained nucleotide sequences for the coxl gene was done using Clustal $\mathrm{W}$ program. The aligned sequences, trimmed to median length (961 bp), were then exported to DnaSP program for the computation of polymorphism in the obtained sequences (Rozas et al. 2017). A maximum-likelihood tree was generated for the coxl sequences along with the reference sequences (FR856886, LC350021, AF416997) keeping Monoliformis monoliformis (AF416998) as an outgroup employing MEGA-X software (Kumar et al. 2018). The obtained nucleotide sequences for the $M$. hirudinaceus isolates were submitted in Genbank database under the accession numbers: MZ683370-MZ683375.

\section{Results}

In total, 59 wild boars were examined among which 38 were categorized as adults whereas 21 were juvenile and subadult. Among the 59 wild boars examined, 23 were females and 36 males. An overall prevalence of $13.6 \%$ was found among the culled wild boars; males had higher infectivity level (16.7\%) than the females $(8.7 \%)$ with non-significant difference in infection levels $\left(\chi^{2}=0.211 ; P=0.629\right)$. Among age cohorts, there was slightly higher proportion of infection in the young animals (14.3\%) compared to the adults (13.2\%) alluding to non-significant difference between the age groups in terms of infection $\left(\chi^{2}=0.01 ; P=0.904\right)$.

A total number of $49 M$. hirudinaceus specimens were collected (range: 1-24 specimen per wild boar), with a mean abundance $(\mathrm{mA})$ of 0.8 and a mean intensity $(\mathrm{mI})$ of 6.1. Males constituted $44.9 \%$ (22 out of 49 ) and females $55.1 \%$ (27 out of 49 ) of the recovered M. hirudinaceus specimens. Total body length ranged from 5.4 in males to $14.1 \mathrm{~cm}$ and 6.2 to $32.5 \mathrm{~cm}$ in female worms. Stereomicroscopical observation of $M$. hirudinaceus showed the cephalic region characterized by the retractile proboscis with typical hooks and epidermal elevation at their insertion point (Fig. 1). The gross examination of the infected wild boars showed a variable dilation of the intestinal lumen and the presence of several parasites at dissection (Fig. 2a and b) attached by means of its apical portion entirely embedded in the wall. The mesenteric lymph nodes were enlarged, and the serosa of the small intestine

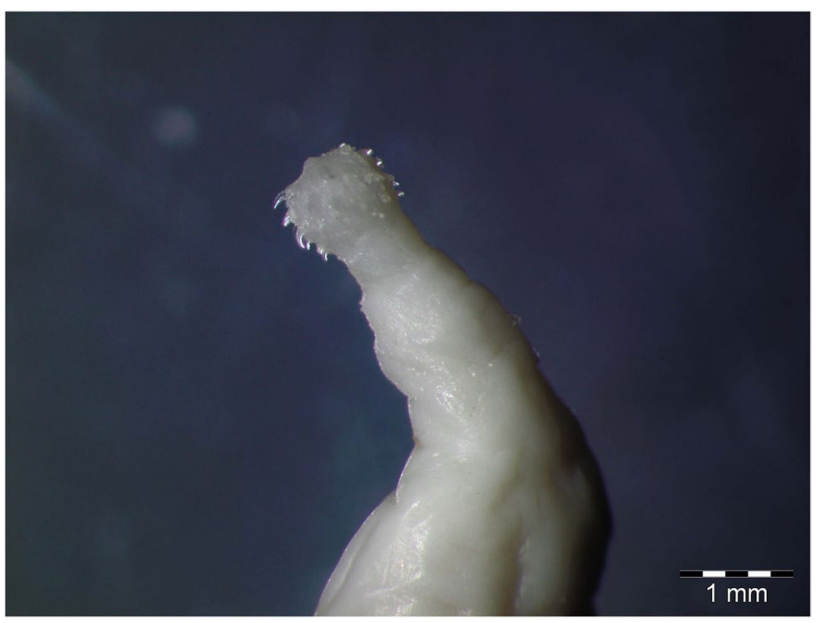

Fig. 1 Stereomicroscopical observation of anterior end of Macracanthorhynchus hirudinaceus with its characteristic spiny head

showed a variable number of roundish small nodules $(\sim 5 \mathrm{~mm})$ surrounded by a hyperemic-hemorrhagic halo (Fig. 2c). In the mucosal surface of the small intestine, the nodules after the parasites removal showed a slight relief, centrally umbilicated (Fig. 2d).

\section{Histological examination}

The histological examination showed a moderate, focal, $0.2 \times 0.2 \mathrm{~mm}$, irregular nodular inflammatory chronic granulomatous reaction oriented around a longitudinal section of an adult acanthocephalan characterized by focally disrupting and ulcerating the intestinal mucosa, extending to the muscular layer and to less extent to the serosa. The parasite was characterized by a thin outer cuticle and a thicker hypodermis (up to $250 \mathrm{um}$ ) with both felted and cross fibers containing lacunar channels, outer circular and inner longitudinal somatic muscle layers, and lemnisci with compressor muscles within a pseudocoelom (Fig. 3). The overlying mucosa was replaced by a moderate number of karyorrhectic neutrophils and less number of eosinophils, admixed with a moderate amount of eosinophilic granular material with cellular debris (lytic necrosis), in turn surrounded by a moderate number of lymphocytes and plasma cells and few epithelioid macrophages. Admixed with and at the borders of the inflammatory nodule were a moderate number of plump reactive fibroblasts and lesser numbers of fibrocytes embedded in a moderate amount of homogeneous intensely eosinophilic fibrillary material (collagen) interpreted as fibroplasia (pyogranuloma). Peripheral myofibers presented increased eosinophilia and loss of the sarcoplasmic cross striation (degeneration) or fragmentation of sarcoplasm with rupture of the cell membrane. 
Fig. 2 Macroscopical examination of the small intestine showing the presence of several worms in the open gut (a) with the spiny-head penetrating the intestinal wall (b), and nodular lesions on the serosa (c) appearing umbilicated in the mucosal surface after removal parasites (d)

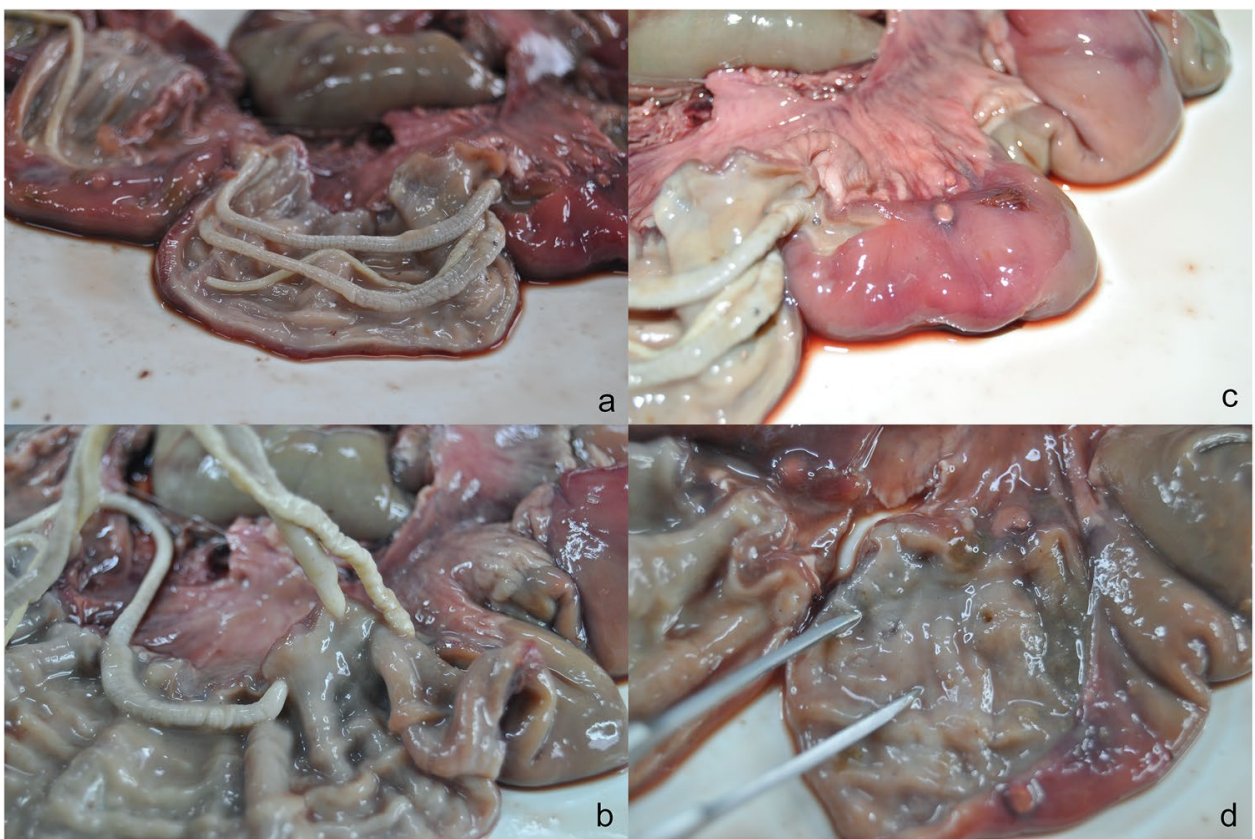

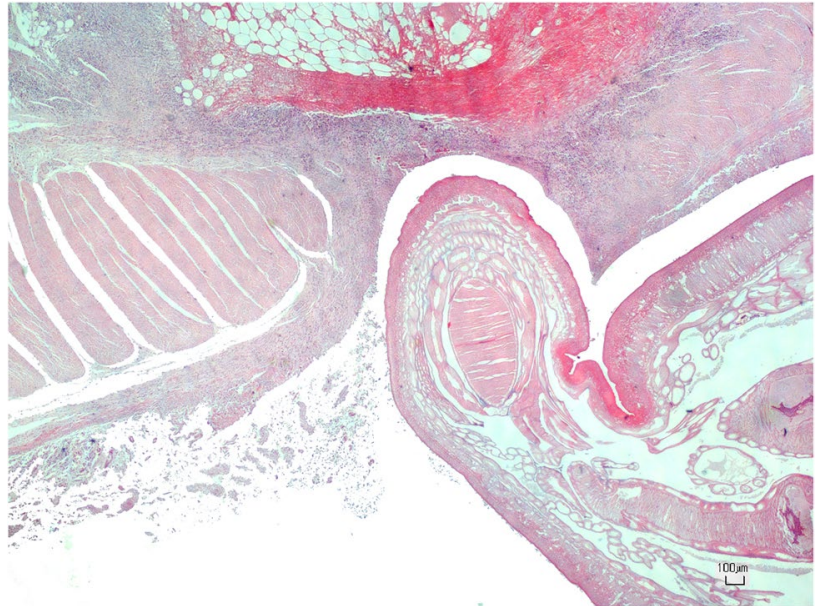

Fig. 3 Histological view of the small intestine H.E.-stained showing a moderate, focal chronic pyogranulomatous and ulcerative enteritis around a longitudinal section of Macracanthorhynchus hirudinaceus

\section{Biomolecular analysis}

The partial coxl nucleotide sequences obtained for the six $M$. hirudinaceus isolates were (>99\%) similar to a sequence from Hungary (FR856886) but showed 89-90\% similarity to an isolate identified from Japan, LC350021. There were 16 nucleotide polymorphic sites within the analyzed fragment of the coxl gene yielding 12 singleton variable sites and 4 parsimony informative sites. There was a single non-synonymous substitution (valine to isoleucine) resulting from a point mutation at first position of the codon at nucleotide number 181 with respect to the reference sequence. It was further revealed that all six nucleotide sequences had interindividual nucleotide variations yielding six different haplotypes having 6.267 average number of nucleotide differences $(k)$ among them. Phylogenetic assessment of the obtained sequences indicated a robust clustering with the reference sequence from Hungary with strong bootstrap values at the relevant tree nodes. The Japanese M. hirudinaceus isolate clustered outside the European population indicating the difference between these parasitic populations. Evolutionary linkages among the sequences are determined by the genetic distance between the populations depicted by the horizontal branch lengths on a phylogenetic tree (Fig. 4).

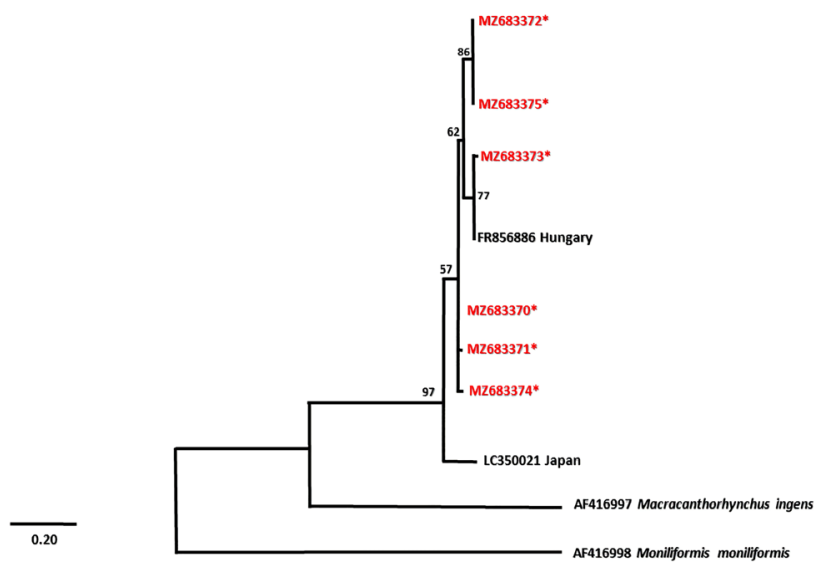

Fig. 4 Maximum-likelihood phylogenetic tree of the coxl mtDNA sequences for Macracanthorhynchus hirudinaceus specimens (written in red with asterisk) indicating positioning with Hungarian isolate. Bootstrap values are represented as number on the tree nodes 


\section{Discussion}

The present survey provides new insights into the epidemiology and molecular characterization of M. hirudinaceus in wild boars for the first time in Sardinia, Italy. In addition, pathomorphological alterations due to this parasite in the gastrointestinal tract are described. As far as we know, no previous epidemiological surveys have been carried out on M. hirudinaceus in wild boars in Sardinia. Furthermore, there are only a few studies on the prevalence of the acanthocephalan in these ungulates in Italy (Magi et al. 2005; Papini et al. 2018) as well as in Europe. Low prevalence observed in the current study $(12.1 \%)$ was quite similar to what was ascertained from central Italy (9.4\%; Papini et al. 2018), southern Italy (Sicily) (11.1\% in feral pigs; Migliore et al. 2021) and Spain (12.1\%, Gassó et al. 2015). Apart from this, M. hirudinaceus has more frequent occurrence (range: $33.0-81.8 \%$ ) in other endemic areas like Morocco (Amayour et al. 2017), Argentina (Ciocco et al. 2019), Iran (Mowlavi et al. 2006; Sarkari et al. 2016; Dodangeh et al. 2018) and Tunisia (Lahmar et al. 2019). The worldwide variations in recorded prevalence could be related to the different climatic conditions and soil composition that may influence the distribution of the dung beetles (Scarabaeidae) which act as intermediate hosts of M. hirudinaceus (Foata et al. 2005; Lizana et al. 2021). Regarding reptiles, little is known about them as potential paratenic hosts of $M$. hirudinaceus, but their varied worldwide distribution may likely contribute to prevalence of M. hirudinaceus in wild boars. Indeed, reptiles act as paratenic hosts of different parasitic zoonoses including acanthocephalans such as Macracanthorhynchus ingens and Macracanthorhynchus cutulinus (Khokhlova, 1986; Hartnett et al., 2018; Mendoza-Roldan et al., 2020). The acanthocephalan $M$. hirudinaceus can infect not only wild boars but also domestic pigs, jackals and red foxes and while it has been rarely in dogs, in which a case of pseudoparasitism or misidentification with Macrachanthorhynchus catulinus may have occurred (Dalimi et al. 2006; Lahmar et al. 2014; Barbosa et al. 2017; Gherman and Mihalca, 2017; Kouam et al. 2018). Incidental hosts include muskrats, squirrels, and humans (Baker, 2007). However, it was established that this parasitosis is most common in pigs raised in free-range and extensive production systems compared to those raised in industrial farms (Barbosa et al. 2017). In Sardinia, the free-ranging pigs are forbidden due to the African Swine Fever eradication programme (PE-ASF15-18), but semi-extensive pig breeding is still present on the island (Anagrafe Nazionale Zootecnica 2020). Furthermore, the intermediate hosts of $M$. hirudinaceus are well distributed in Sardinia (Carpaneto et al. 2011).
The prevalence found in wild boars in current study, may also represent a sanitary concern for the health status of domestic pigs, particularly in areas where semiextensive farming allows uncontrolled contacts with wild species that favours the transmission of viral diseases. The ingestion of the intermediate host harboring cystacanth larvae by the pigs could lead to economic losses for farmers primarily due to slow growth and weight loss typical of M. hirudinaceus severe infection (Barbosa et al. 2017). Macracanthorhynchus hirudinaceus has been reported in humans from China (Leng et al. 1983; Zhong et al. 1983), Thailand (Hemsrichart et al. 1983; Radomyos et al. 1989) and Russia (Schmidt 1971) to date. There is no description of M. hirudinaceus in humans in Italy thus far; however, the possibility of indirect transmission of this parasite to humans could not be excluded. Indeed, the proximity of wild animals to humans has thrived recently, especially during the lockdown for the COVID-19 pandemic, as documented also in Sardinia (Bressan 2020).

The prevalence of neglected and zoonotic parasites such as M. hirudinaceus recorded in wild boars in Sardinia, suggests the need to carry out further investigations throughout the island on wild boars, which are known to harbor other parasitic zoonoses such as Trichinella spp. (Bandino et al. 2015), Echinococcus granulosus sensu lato/s.l. (Paoletti et al. 2019; Sgroi et al. 2019) and Toxoplasma gondii (Sgroi et al. 2020).

Based on present study the age of wild boars seemed not to represent a risk factor for infection, since no differences were found between the prevalence in young and adults, unlike to what was reported in Sicily (Migliore et al. 2021), where M. hirudinaceus was identified only in young feral pigs ( $<1$-yr-old), and in Iran (Mowlawi et al. 2006) where adult wild boars were comparatively more infected than young ones.

Pathological examination showed severe damage of the small intestine wall, with the anterior part of the thornheaded worm penetrated into the sub mucosal layer of boar intestine and caused severe inflammation. The findings of this study are in line with those reported by previous studies (Mowlavi et al. 2006; Sarkari et al. 2016; Migliore et al. 2021).

Identification of epidemiological and pathogenic status of a parasite is of paramount importance to understand its biology and infectivity. There is accumulating evidence regarding the reliability of the morphological studies alone as they may result in misidentification of the species (Huston et al. 2020). Our study combined both morphological and molecular approaches to characterize the $M$. hirudinaceus isolates retrieved from the wild boars in Sardinia. For molecular analysis, the study involved sequencing for the coxl gene which is the most common and reliable marker in population genetics and phylogenetic studies. So far, molecular 
data on M. hirudinaceus are very limited; there are only two sequences in the NCBI database, one of which is a complete genome from Hungary (FR856886) whereas, the other is partial coxl sequence from Japan (LC350021). It is very interesting to mention that all six nucleotide sequences for the partial coxl gene had high genetic variability which shows an expanding M. hirudinaceus population within this locality. The European sequences were more similar to each other compared to the Japanese sequence displaying heterogeneity among the different geographical populations. Only two reports of $M$. hirudinaceus occurrence are reported in Japan and are yet to be established whether this species is accidentally introduced or has endemic status (Kamimura et al. 2018). But the clustering of Japanese isolate separately from the European population shows that independent factors are operative at different geographical areas affecting the genetic structure of the species. Due to scarcity of investigations and lack of molecular data, no studies on gene flow among the M. hirudinaceus populations could be carried out which limits our understanding of its geographical spread and population structure.

\section{Conclusion}

This preliminary investigation involving pathomorphological and molecular approaches to characterise acanthocephalan species, $M$. hirudinaceus, from Italy has provided an insight into level of infection and extent of endemism of this parasitic species in southern part of Europe. Amid lack of epidemiological and genetic information on this zoonotic parasite from European side, continued efforts are required to generate molecular data to find relationships among different regional and endemic populations. On the other side, it is equally important to find out the transmission routes of this parasite to limit its spread to humans and other host species and devise suitable strategies for its control.

Funding This research was partially funded by "Fondo di Ateneo per la ricerca 2020" of Prof. Antonio Scala and Prof. Antonio Varcasia of the University of Sassari, Italy.

\section{Declarations}

Conflict of interest The authors declare no competing interests.

\section{References}

Amayour A, El Alaoui Z, Alkhali A, Hassouni T, Elkharrim K, Belghyti D (2017) Presence of very high prevalence of Macracanthorhynchus hirudinaceus infection in Wild Boars (Sus scrofa barbarus) in El Hajeb province, Middle Atlas, Morocco. J Entomol Zool Stud 5:1784-1787

Anagrafe Nazionale Zootecnica (2020). https://www.vetinfo.it/j6 statistiche/index.html\#/report-pbi/31_Accessed 23 April 2021

Baker GD (2007) Flynn's parasites of laboratory animals. - Blackwell Publishing Ltd 9600 Garsington Road, Oxford OX4 2DQ, UK.

Bandino E, Goddi L, Mulas M, Murgia MC, Soddu M, Marucci G, Pezzotti P, Cabras PA, Pozio E (2015) Trichinella britovi from domestic to wild animals of Sardinia, Italy. Vet Parasitol 212:262-266. https://doi.org/10.1016/j.vetpar.2015.07.020

Barbosa JD, Silva JB, Reis ARB, Bomjardim HA, Driemeier D, Salvarani FM, Oliveira CHS, Oliveira CMC, Brito M (2017) Identification of Macracanthorhynchus hirudinaceus, Stephanurus dentatus and Trichuris suis in Native Pigs on Marajó Island. J Vet Sci Med Diagn 6:4. https://doi.org/10.4172/2325-9590.1000237

Bonelli P, Dei Giudici S, Peruzzu A, Piseddu T, Santucciu C, Masu G, Mastrandrea S, Delogu ML, Masala G (2020) Genetic diversity of Echinococcus granulosus sensu stricto in Sardinia (Italy). Parasitol Int 77:102120. https://doi.org/10.1016/j.parint.2020.102120

Bressan D (2020) https://www.forbes.com/sites/davidbressan/2020/03/ 20/animals-roam-freely-in-italian-cities-with-humans-in-lockd own/?sh=c08302179565 Accessed 23 April 2021

Carpaneto G, Piattella E, Dellacasa G, Dellacasa M, Pittino R, Mazziotta A (2011) The lamellicorn beetles of southern Sardinia (Coleoptera: Scarabaeoidea). Conservazione Habitat Invertebrati 5:353-387

Ciocco R, Carpinetti B, Rojas P, Castresana G, Notarnicola J (2019) Endoparásitos de una población de cerdos silvestres (Sus scrofa) en Bahía Samborombón, Buenos Aires, Argentina. Rev Mex Biodivers 90. https://doi.org/10.22201/ib.20078706e.2019.90.2851

Dalimi A, Sattari A, Motamedi G (2006) A study on intestinal helminthes of dogs, foxes and jackals in the western part of Iran. Vet Parasitol 142:129-133. https://doi.org/10.1016/j.vetpar.2006. 06.024

Dodangeh S, Azami D, Daryani A, Gholami S, Sharif M, Mobedi I, Sarvi S, Soleymani E, Rahimi MT, Pirestani M, Gohardehi S, Bastani R (2018) Parasitic helminths in wild boars (Sus scrofa) in Mazandaran Province, Northern Iran. Iran J Parasitol 13:416-422

Foata J, Culioli JL, Marchand B (2005) Helminth fauna of wild boar in Corsica. Acta Parasitol 50:168-170

Fredriksson-Ahomaa M (2018) Wild boar: a reservoir of foodborne zoonoses. Foodborne Pathog Dis 16:153-165. https://doi.org/10. 1089/fpd.2018.2512

Gassó D, Feliu C, Ferrer D, Mentaberre G, Casas-Díaz E, Velarde R, Fernández-Aguilar X, Colom-Cadena A, Navarro-Gonzalez N, López-Olvera JR, Lavín S, Fenández-Llario P, Segalés J, Serrano E (2015) Uses and limitations of faecal egg count for assessing worm burden in wild boars. Vet Parasitol 209:133-137. https:// doi.org/10.1016/j.vetpar.2015.02.006

Gherman CM, Mihalca AD (2017) A synoptic overview of golden jackal parasites reveals high diversity of species. Parasit Vectors 10:419. https://doi.org/10.1186/s13071-017-2329-8

Hartnett EA, Léveillé AN, French SK, Clow KM, Shirose L, Jardine CM (2018) Prevalence, distribution, and risk factors associated with Macracanthorhynchus ingens infections in raccoons from Ontario, Canada. J Parasitol 104:457-464. https://doi.org/10. 1645/17-202

Hemsrichart V, Pichyangkura C, Chitchang S, Vutichamnong U (1983) Eosinophilic enteritis due to Macracanthorhynchus hirudinaceus infection: report of 3 cases. J Med Assoc Thai 66:303-310

Huston DC, Cribb TH, Smales LR (2020) Molecular characterisation of acanthocephalans from Australian marine teleosts: proposal of a new family, synonymy of another and transfer of taxa between orders. Syst Parasitol 97:1-23. https://doi.org/10.1007/ s11230-019-09896-2 
Iacolina L, Pertoldi C, Amills M, Kusza S, Megens H, Bâlteanu VA, Bakan J, Cubric-Curic V, Oja R, Saarma U, Scandura M, Šprem N, Stronen AV (2018) Hotspots of recent hybridization between pigs and wild boars in Europe. Sci Rep 18:8. https://doi.org/10. 1038/s41598-018-35865-8

Iacolina L, Scandura M, Goedbloed DJ, Alexandri P, Crooijmans RP, Larson G, Archibald A, Apollonio M, Schook LB, Groenen MA, Megens HJ (2016) Genomic diversity and differentiation of a managed island wild boar population. Heredity (edinb) 116:6067. https://doi.org/10.1038/hdy.2015.70

ISPRA, 2020. https://www.isprambiente.gov.it/it/archivio/notizie-enovita-normative/notizie-ispra/2019/09/cinghiali-tutti-ne-parla no-e-ormai-sono-quasi-tendenza-intervista-a-esperto-ispra Accessed 15 October 2021.

ISSG-IUCN SSC Invasive Species Specialist Group (2013) Global Invasive Species Database (GISD). IUCN SSC Invasive Species Specialist Group. http://www.iucng isd.org/gisd/

Kamimura K, Yonemitsu K, Maeda K, Sakaguchi S, Setsuda A, Varcasia A, Sato H (2018) An unexpected case of a Japanese wild boar (Sus scrofa leucomystax) infected with the giant thorny-headed worm (Macracanthorhynchus hirudinaceus) on the mainland of Japan (Honshu). Parasitol Res 117:2315-2322. https://doi.org/10. 1007/s00436-018-5922-7

Khokhlova IG (1986) Acanthocephalans of terrestrial vertebrates from the fauna of USSR. Nauka, Moscow, p 277

Kouam MK, Ngueguim FD, Kantzoura V (2018) Internal parasites of pigs and worm control practices in Bamboutos, Western Highlands of Cameroon. J Parasitol Res 2018:8242486. https://doi. org/10.1155/2018/8242486

Kumar S, Stecher G, Li M, Knyaz C, Tamura K (2018) MEGA X: molecular evolutionary genetics analysis across computing platforms. Mol Biol Evol 35:1547. https://doi.org/10.1093/molbev/ msy096

Lahmar S, Boufana B, Ben Boubaker S, Landolsi F (2014) Intestinal helminths of golden jackals and red foxes from Tunisia. Vet Parasitol 204:297-303. https://doi.org/10.1016/j.vetpar.2014.05.038

Lahmar S, Torgerson PR, Mhemmed H, Tizaoui L, Mhadhbi N, Bani A, Driss H, Ghrissi N, Makhzoumi M, Ben Houidi A, Dhibi M, Said Y, Pozio E, Boufana B (2019) Cystic echinococcosis and other helminth infections of wild boar in northeastern and northwestern regions of Tunisia. Parasitology 146:1263-1274. https://doi.org/ 10.1017/S0031182019000532

Leng YJ, Huang WD, Liang PN (1983) Human infection with Macracanthorhynchus hirudinaceus Travassos, 1916 in Guangdong Province, with notes on its prevalence in China. Ann Trop Med Parasitol 77:107-109. https://doi.org/10.1080/00034983.1983. 11811681

Lizana V, Gortazar C, Prats R, Sáchez-Isarria MA, Carrión MJ, Cardells J (2021) Macracanthorhynchus hirudinaceus in expanding wild boar (Sus scrofa) populations in Eastern Spain. Parasitol Res 120:919-927. https://doi.org/10.1007/s00436-020-06975-y

Lombardini M, Meriggi A, Fozzi A (2017) Factors influencing wild boar damage to agricultural crops in Sardinia (Italy). Curr Zool 63:507-514. https://doi.org/10.1093/cz/zow099

Magi M, Bertani M, Dell'Omodarme M, Prati MC (2005) Necropsy and coprology in wild boar (Sus scrofa) in Livorno Mountain Park (Tuscany, central Italy). Parassitologia 46:311-313

Marchiondo AA (2019) Acanthocephala, In: Marchiondo A, Cruthers L, Fourie J (eds) Parasiticide Screening, Volume 2. Academic Press, pp 337-343. https://doi.org/10.1016/B978-0-12-816577-5. 00008-9.

Massei G, Toso S (1993) Biologia e gestione del cinghiale. In: Documenti tecnici 5 (eds.). Bologna, Italy. Istituto Nazionale per la Fauna Selvatica, pp 1-75.

Massei G, Kindberg J, Licoppe A, Gačić D, Šprem N, Kamler J, Baubet E, Hohmann U, Monaco A, Ozoliņš J, Cellina S, Podgórski
T, Fonseca C, Markov N, Pokorny B, Rosell C, Náhlikq A (2015) Wild boar populations up, numbers of hunters down? A review of trends and implications for Europe. Pest Manag Sci 71:492-500. https://doi.org/10.1002/ps.3965

Mendoza-Roldan JA, Modry D, Otranto D (2020) Zoonotic parasites of reptiles: a crawling threat. Trends Parasitol 36:677-687. https://doi.org/10.1016/j.pt.2020.04.014

Migliore S, Puleio R, Gaglio G, Vicari D, Seminara S, Sicilia ER, Galluzzo P, Cumbo V, Loria GR (2021) A neglected parasite: Macracanthorhynchus hirudinaceus, first report in feral pigs in a Natural Park of Sicily (Southern Italy). Front Vet Sci 8:659306. https://doi.org/10.3389/fvets.2021.659306

Mowlavi G, Massoud J, Mobedi I, Solaymani-Mohammadi S, Gharagozlou M, Mas-Coma S (2006) Very highly prevalent Macracanthorhynchus hirudinaceus infection of wild boar Sus scrofa in Khuzestan province, south-western Iran. Helminthologia 43:86-91. https://doi.org/10.2478/s11687-006-0017-x

Paoletti B, Della Salda L, Di Cesare A, Iorio R, Vergara A, Fava C, Olivastri A, Dessì G, Scala A, Varcasia A (2019) Epidemiological survey on cystic echinococcosis in wild boar from Central Italy. Parasitol Res 118:43-46. https://doi.org/10.1007/ s00436-018-6112-3

Papini RA, Vannucci S, Rocchigiani G, Nardoni S, Mancianti F (2018) Prevalence of Toxoplasma gondii and potentially zoonotic helminths in wild boars (Sus scrofa) hunted in Central Italy. Maced Vet Rev 41:83-93. https://doi.org/10.2478/macve trev-2018-0012

Pavlović IN, Kulišić ZB, Tambur Z, Protić NM (2010) Scarabidae: intermediate host for Macracanthorhynchus hirudinaceus. Proc Nat Sci Matica Srpska Novi Sad 119:89-95. https://doi.org/10. 2298/ZMSPN1019089P

PE-ASF15-18, Regional Decree Number 50/17, 16 December 2014, Retrieved from http://www.assindnu.it/attachments/article/3219/ Piano_eradicazione_dicembre_2014.pdf Accessed 23 April 2021.

Petrochenko VI (1958) Acanthocephala (thornyheads) of domestic and wild animals, vol II. USSR Academy of Sciences, Moscow ((in Russian))

Pilo C, Mereu Piras P, Fois F, Liciardi M (2012) High burden infection by Macracanthorhynchus hirudinaceus (Archiacanthocephala: Oligacanthorhynchidae) in two Sardinian wild boars: a case report. XXVII Congresso Nazionale SoIPa, Alghero (SS) 26-29 Giugno 2012.

Pittiglio C, Khomenko S, Beltran-Alcrudo D (2018) Wild boar mapping using population-density statistics: from polygons to high resolution raster maps. PLoS ONE 13:e0193295. https://doi.org/ 10.1371/journal.pone.0193295

Radomyos P, Chobchuanchom A, Tungtrongchitr A (1989) Intestinal perforation due to Macracanthorhynchus hirudinaceus infection in Thailand. Trop Med Parasitol 40:476-477

Richardson DJ (2005) Identification of cystacanths and adults of Oligacanthorhynchus tortuosa, Macracanthorhynchus ingens, and Macracanthorhynchus hirudinaceus based on proboscis and hook mophometrics. J Arkansas Acad Sci 59:205-209

Rozas J, Ferrer-Mata A, Sánchez-Del Barrio JC, Guirao-Rico S, Librado P, Ramos-Onsins SE, Sánchez-Gracia A (2017) DnaSP 6: DNA sequence polymorphism analysis of large data sets. Mol Biol Evol 34:3299-3302. https://doi.org/10.1093/molbev/msx248

Sarkari B, Mansouri M, Najjari M, Derakhshanfar A, Mowlavi G (2016) Macracanthorhynchus hirudinaceus: the most common helminthic infection of wild boars in southwestern Iran. J Parasit Dis 40:1563-1566. https://doi.org/10.1007/s12639-015-0728-3

Schmidt GD (1971) Acanthocephalan infections of man, with two new records. J Parasitol 57:582-584

Setsuda A, Varcasia A, Scala A, Ozawa S, Yokoyama M, Torii H, Suzuki K, Kaneshiro Y, Corda A, Dessì G, Tamponi C, Cabras PA, Sato H (2020) Gongylonema infection of wild mammals in 
Japan and Sardinia (Italy). J Helminthol 94. https://doi.org/10. 1017/S0022149X18001001

Sgroi G, Varcasia A, Dessì G, D’Alessio N, Tamponi C, Saarma U, Laurimäe T, Kinkar L, Santoro M, Caputo V, Sarnelli P, Fusco G, Varuzza P, Fioretti A, Scala A, Veneziano V (2019) Cystic echinococcosis in wild boars (Sus scrofa) from southern Italy: epidemiological survey and molecular characterization. Int J Parasitol Parasites Wild1 9:305-311. https://doi.org/10.1016/j.ijppaw. 2019.04.013

Sgroi G, Viscardi M, Santoro M, Borriello G, D’Alessio N, Boccia F, Pacifico L, Fioretti A, Veneziano V, Fusco G (2020) Genotyping of Toxoplasma gondii in wild boar (Sus scrofa) in southern Italy: epidemiological survey and associated risk for consumers. Zoonoses Public Health 67:805-813. https://doi.org/10.1111/zph. 12762

Solaymani-Mohammadi S, Mobedi I, Rezaian M, Massoud J, Mohebali M, Hooshyar H, Rokni M (2003) Helminth parasites of the wild boar, Sus scrofa, in Luristan province, western Iran and their public health significance. J Helminthol 77:263-267. https://doi. org/10.1079/JOH2003168
Weber M, Wey-Fabrizius AR, Podsiadlowski L, Witek A, Schill RO, Sugár L, Herlyn H, Hankeln T (2013) Phylogenetic analyses of endoparasitic Acanthocephala based on mitochondrial genomes suggest secondary loss of sensory organs. Mol Phylogenet Evol 66:182-189. https://doi.org/10.1016/j.ympev.2012.09.017

Wilson CJ (2005) Feral wild boar in England. Status, impact and management. A report on behalf of Defra European Wildlife Division. Department for Environment, Food and Rural Affairs, London, p 47

Zhong HL, Feng LB, Wang CX (1983) Human infection with Macracanthorhynchus hirudinaceus causing serious complications in China. Chin Med J 96:661-668

Publisher's note Springer Nature remains neutral with regard to jurisdictional claims in published maps and institutional affiliations. 